\title{
The efficacy of pre-emptive analgesia on pain management in total knee arthroplasty: a mini-review
}

\author{
Jianda $\mathrm{Xu}^{1+}$, Huan $\mathrm{Li}^{2+}$, Chong Zheng ${ }^{1}$, Bin Wang ${ }^{1}$, Pengfei Shen ${ }^{1}$, Zikang Xie ${ }^{1}$ and Yuxing $\mathrm{Qu}^{1 *}$
}

\begin{abstract}
Total knee arthroplasty (TKA) is considered a cost-effective and efficacious treatment for patients with end-stage knee arthritis. Meanwhile, TKA has been regarded as one of the most painful orthopaedic surgeries. Pain control after TKA remains a challenging task. Many analgesic innovations are used to reduce the level of pain, but none has been proven to be the optimum choice till now. Multimodal analgesia incorporates the use of analgesic adjuncts with different mechanisms of action to enhance postoperative pain management. This approach is a preferable choice in relieving postoperative pain with minimum side effects. This paper aims to review pre-emptive analgesia for pain management in TKA. We reviewed the application of pre-emptive analgesia, its physiological mechanism, and the techniques.
\end{abstract}

Keywords: Pre-emptive analgesia, Pain management, Total knee arthroplasty, Mechanism, Methods

\section{Introduction}

Total knee arthroplasty (TKA) is considered a costeffective and efficacious treatment for patients with end stage knee arthritis [1]. Meanwhile, TKA has been regarded as one of the most painful orthopaedic surgeries [2]. Pain can impact significantly upon patient's rehabilitation, as well as physical, emotional and social wellbeing [3]. Many analgesic innovations (such as intravenous patient-controlled analgesia, peripheral nerve blockade, and continuous epidural analgesic techniques) are used to reduce the level of pain, but none has been proven to be the optimum choice till now [4].

Preemptive analgesia (PA) is defined as an antinociceptive treatment that prevents the establishment of altered central processing of afferent input, which amplifies pain after TKA [5]. The idea of PA was first proposed by Crile [6] in 1913 and disseminated by Wall and Woolf [7]. Woolf [8] reported that PA could change the time and magnitude of pain postoperatively by decreasing central sensory processing. Bach et al. [9] in 1988

\footnotetext{
* Correspondence: quyuxing8848@163.com

†Jianda Xu and Huan Li are co-first authors

'Department of Orthopaedics, Changzhou Traditional Chinese Medical

Hospital, Nanjing University of Traditional Chinese Medicine, 25 North

Heping Road, Changzhou 213000, Jiangsu Province, China

Full list of author information is available at the end of the article
}

found that 3 days of continuous epidural morphine plus bupivacaine administered prior to amputation reduced the incidence of phantom limb pain 6 months later compared with a control group that did not receive an epidural before amputation. In an experimental study, Coderre et al. [10] found PA prevented the nervous system from experiencing pain from the surgery and thereby reduced postoperative pain as well.

PA focuses on postoperative pain control and the prevention of central sensitization and chronic neuropathic pain by providing analgesia administered preoperatively but not after surgical incision [11]. PA has protective effect on the nociceptive system, which could significantly reduce the level of pain and decrease the risk for the development of chronic pain [8]. Because the pain mediators in peripheral and central nervous systems are inhibited, the duration and level of postoperative pain is decreased. The benefits from PA will outlast their normal pharmacological duration of action.

Multimodal analgesia incorporates the use of analgesic adjuncts with different mechanisms of action to enhance postoperative pain management [12]. This approach is a preferable choice in relieving postoperative pain with minimium side effects. Skinner et al. [13] found that PA with multiple non-narcotic medications used in a 
stacked modality could significantly reduce postoperative pain. PA is an important part of multimodal analgesia.

This paper aims to review PA for pain management in TKA. Three questions are raised as a framework of this review:

(1) Why should we care about PA?

(2) What's the physiological mechanism of PA?

(3) What are the techniques of PA?

\section{Why should we care about PA?}

Compared with a similar analgesic treatment after TKA, PA improves the pain relief apparently [10]. Shlaifer et al. [11] found that preemptive periacetabular bupivacaine provided a better postoperative pain relief than intra-articular injection. Gottchalk et al. [12] advocated that preemptive epidural analgesia significantly attenuated postoperative pain during hospitalization and even after hospital discharge for a long time.

The tissue noxious stimuli activate pain that often launches a cascade of alternative reactions, which brings a central and peripheral sensitization. Both peripheral sensitization (with a reduction in the threshold) and central sensitization (with excitability of spinal neurons) contribute to hypersensitivity state of injury pain [8]. Peripheral sensitization usually has a lower threshold, while central sensitization brings hyper-excitability to uninjured tissues [9]. These alterations amplify the severity of the pain by elevating response to noxious stimuli. Therefore, pain management should include both the nociception and central nervous system related to tissue trauma. Prescribing analgesics can effectively reduce the pain after TKA, but this management is suboptimal. The new strategy is to prevent abnormal sensitization of peripheral and central neurons.

The knee pain after TKA is a sharp pain. Adequate and appropriate postoperative analgesia allows an earlier rehabilitation, resulting in better joint function. PA can achieve a better pain control, faster post-operative functional recovery, and leads to less adverse events [13]. Some researches showed that efficacy of the analgesic drugs are affected by patient's personality and behaviors. Patients with less anxiety and depression are associated with lower levels of joint pain and lower use of opioid analgesics [14]. The patients who undergo TKA usually have a long earlier history of knee pain, associated with higher anxiety. Clearly, the persistent afferent barrage from the wound (free endings of primary afferent neurons) can induce severe acute pain postoperatively, especially at the time that spinal anaesthetic has worn off. Since the postoperative pain tends to be severe, PA has been considered to play an important role in the pain management [15]. In patients receiving total hip arthroplasty, preoperative intravenous administration of ketorolac often caused less pain and delayed the time of postoperative opioid consumption [16]. Briefly, the PA is associated with less subsequent pain postoperatively.

\section{What's the physiological mechanism of PA?}

The physiological mechanism of PA is complex and involves the pain pathways. The pain pathways involved in reflex response that is entirely within the spinal cord, and the withdrawal response occurs without the sensation of pain. When the pain withdrawal reflex fails to disappear long after the triggering event. Two-neuron arc is the simplest form, fastest-responding and consists of afferent and efferent neurons. One example is the knee-jerk reflex. The three-neuron arc reflex arc consists of afferent neurons, interneurons, and efferent neurons. Afferent neurons conduct impulses to the central nerve system from the receptors. Efferent neurons conduct impulses from the central nerve system to effectors (muscle or glandular tissue).

Noxious stimuli are stimuli that elicit tissue damage and activate nociceptors. Nociceptors are sensory receptors (primary afferent neurons) that detect signals from damaged tissues and indirectly also respond to chemicals released from the damaged tissues. The noxious stimuli usually produce two types of sensory inputs, i.e., tissue damaging noxious stimuli and inflammatory stimuli from algetic substances (prostaglandins, 5-HT, bradykinin, histamine, and so on) [17]. Many inflammatory mediators increase the sensitivity of nociceptors. At the same time, the peripheral terminals of nociceptors convert chemical, mechanical or thermal energy to electrical activities, which are subsequently transmitted to the dorsal horn of the central nervous system [9]. Based on the types of stimuli and their locations, nociceptors are subdivided into several groups, including myelinated $\mathrm{A} \delta$ fiber nociceptors for mechanical and thermal injuries; unmyelinated $\mathrm{C}$ nociceptors for strong mechanical, thermal and/or chemical stimuli. The A $\delta$-fiber nociceptors mediate the 'first pain' (rapid, sharp pain), while $\mathrm{C}$ nociceptors mediate 'second pain' (delayed pain).

The secondary nociceptive neurons in the dorsal horn receive the pain signals from nociceptors, which respond for further transmission of pain sensation. These nociceptive neurons include nociceptive-specific neurons (just for signals in A $\delta$-fiber nociceptors) and widedynamic-range neurons (for signals in $A \delta$-fiber and $\mathrm{C}$ fiber nociceptors and non-nociceptive impulses in $A \beta$ fiber nociceptors). The activity of these secondary nociceptive involves the balance between excitatory and inhibitory factors from different transmitted elements.

If the severity of injuries is below the threshold of tolerance, there exists a consistent and proportionate relationship between the stimulus and pain reaction. Whereas, the damage will initiate an alternative 
transmission process. The central and peripheral sensitization are induced. The touch signals from $A \beta$ fiber nociceptors will be recognized as pain signals by wide-dynamic-range neurons. The pain-promoting substances from the free endings of primary afferent neurons and extraneural sources result in a peripheral sensitization. The signals from $\mathrm{A} \delta$-fiber and $\mathrm{C}$-fiber nociceptors will be amplified, which brings pain sensation due to a lower damage. A memory trace of pain emerges with a prolonged alternative pain reaction [18].

Therefore, pre-emptive measures interrupting these alternative processes are needed for better analgesia. PA is an effective supplement to multimodal analgesia approach in relieving postoperative pain. The combined approach may contribute eventually to a longer postoperative painless course, earlier mobilization, and better knee joint function [19].

\section{What are the techniques of PA?}

Given the importance of PA, we tried many different analgesics or analgesic interventions. These interventions direct at the periphery, and transmit along the afferent/ efferent pathways and central neurons [20]. These analgesia strategies can also interfere with one or more sites along the pain pathway. These trials include nonsteroidal anti-inflammatory drugs (NSAIDs), opioids, N-methyl-Daspartate receptor antagonists, peripheral local anesthetics, and systemic antiepileptics.

\section{NSAIDs}

NSAIDs, as important pain killers, have antipyretic actions with less postoperative side effects compared with opioids [21]. The nonselective NSAIDs inhibit cycloxygenase (COX) enzymes covering COX-1 and COX-2 enzymes. Considering the disturbance of normal platelet function and gastrointestinal toxicity by inhibiting COX1 enzyme, the selective COX-2 inhibitors offer a better choice for perioperative application. Some researcher suggested that preoperative administration of NSAIDs could prevent the secondary prostaglandin hyperalgesia. The prostaglandin and bradykinin releases are the main causes of inflammatory pain, which alter nociceptive sensitivity and sensitivity threshold [22].

In orthopedic surgeries, NSAIDs have been widely used to reduce postoperative pain. Kashefi et al. [23] reported that preoperative oral celecoxib at the dose of $200 \mathrm{mg}$ every $2 \mathrm{~h}$ could effectively control the postoperative pain in patients who underwent lower extremity orthopedic surgeries. Compared with celecoxib and placebo, etoricoxib was more effective for PA in controlling postoperative pain [24]. A new research proposed that, in patients who underwent TKA, PA improved the analgestic effect of multimodal analgesic regime, reduced inflammatory reaction, and accelerated functional recovery during the first postoperative week [25]. However, PA didn't further improve long-term function of the knee. O'Hanlon et al. [26] suggested tenoxicam should be given intramuscularly 30 min preoperatively. The striking advantages were the lower total doses of demerol and diclofenac, and the significantly extended time to first analgesic requirements.

In controlling thermal hyperalgesia, NSAIDs have a comparable antagonist effect on N-methyl-D-aspartate receptor and serve as useful analgesic adjuncts to the control of acute pain [27]. In addition to the central mechanism, NSAIDs can also contribute to the prevention of spinal prostanoid synthesis by reducing release of neurotransmitters from reflex arc of pain [28]. The effect of PA is caused by their actions of inhibiting the synthesis of prostaglandins through the inactivation of cyclooxygenase.

There are some contradicting and even negative results. By comparing combined pre- and postoperative NSAIDs and post-operative NSAIDs alone, Murphy [29] found that pre-emptive administration of indomethacin brought the equivalent postoperative analgesia and opioids consumption.

\section{Opioids}

Opioids are mostly used analgesics for pain control and they work by interacting with opioid receptors. Some researchers pointed out that preemptive use of intrathecal morphine injection had a strong and long-lasting effect in postoperative analgesia [30]. Campiglia et al. [31] reported that sublingually-given morphine sulphate in abdominal surgery provided a better pain control over a period of $48 \mathrm{~h}$ postoperatively. However, for patients receiving abdominal hysterectomy, intravenous alfentanil either at induction or one minute after skin incision brought no difference in postoperative pain control [32].

Chong et al. [33] found that intravenous infusion of morphine for PA was more effective in preventing the occurrence of phantom limb pain. Preemptive opioid analgesics in orthopedic surgeries could delay the time of requesting analgesics postoperatively [34].

\section{$\mathrm{N}$-methyl-D-aspartate receptor antagonists}

There is a controversy about the role of N-methyl-D-aspartate receptor antagonists (NMDA antagonists) in PA. The extensive administration of NMDA-channel antagonists has been considered an effective way to block central sensitization. Oliveira et al. [35] blocked NMDA receptors in the neurons of dorsal horn of spina, resulting in inhibition of central sensitization triggered by nociceptive stimulations. Malmberg et al. [27] reported that spinal administration of NMDA could induce thermal hyperalgesia. However, a meta-analysis concluded that pre-emptive ketamine was less effective in controlling postoperative pain [18]. Li et al. [36] found that 
preemptive administration of dextromethorphan $30 \mathrm{~min}$ before operation significantly reduced postoperative fentanyl consumption and the incidence of nausea and vomiting in the patients given patient-controlled intravenous analgesia. In patients with TKA, Yeh et al. [37] failed to observe any PA effect of dextromethorphan on postoperative pain in patients under epidural anesthesia. However, dextromethorphan given either before or after surgery augmented the effect of another analgesic (morphine) and thereby achieved a better pain relief.

Up to now, the clinical efficacy of NMDA antagonists in PA remains controversial.

\section{Peripheral local anesthetics}

Local peripheral anesthetics inhibit pain transmission by stabilizing the cell membrane and controlling the sodium influx [38]. One research found that local PA couldn't improve the level of pain relief compared with a similar post-incisional infiltration [39, 40]. However, many studies still argued that preincisional infiltration with local anesthetics produced a better pain relief compared with either spinal anesthesia or general anesthesia alone. Lower level of pain would last a few more days [41]. Joel et al. [42] proposed that rectal administration of PA brought an unexpected benefit and reduced postoperative dose of opioids. PA was a key approach for postoperative analgesia. Gordon et al. [43] proposed that administration of bupivacaine (a long-acting local anesthetic agent) could block the peripheral nociceptive input and the development of central hyperexcitability. The analgesia brought less pain and analgesic consumption. A study about preemptive epidural analgesia in laparoscopic radical hysterectomy for cervical cancer revealed that preemptive epidural analgesia could prevent postoperative pain and control cytokine response [43]. Dahl-V et al. [44] reported that pre-incisional infiltration with local anaesthetics had a tendency toward faster awakening, earlier recovery, and less opioid use postoperatively. Compared with the administration at the end of surgery, preemptive intra-articular injection of morphine and bupivacaine provided a longer analgesia time [45].

\section{Systemic antiepileptics}

Systemic antiepileptics are GABA analogues that are originally used as therapeutic agent for partial seizures. The central and peripheral sensitization are considered to be an important mechanism of postoperative pain [46]. GABA analogues can effectively suppress the hyperalgesia of dorsal horn neurons. The mechanism is that gabapentin and pregabalin can bind to alpha-2 delta subunit of voltage-gated calcium channels to induce their analgesic action. On binding to alpha-2 delta subunit, pregabalin was six times more potent than gabapentin with less adverse events [47]. A review showed that gabapentin and pregabalin used as PA could effectively reduce postoperative analgesic rescue and delay the first time of analgesic requirement [48]. Gabapentin reduces the opioid consumption at the first $24 \mathrm{~h}$ postoperatively, but the effect is not dose-depenent. The highest safe doses of gabapentin and pregabalin are $1200 \mathrm{mg}$ and $300 \mathrm{mg}$, respectively. Saraswat [49] proposed that the first time of analgesic requirement in gabapentin group was earlier than in group.

\section{Conclusion}

Always, prevention is preferable to cure. PA is a good supplement to multimodal approaches, and is confirmed to be a better analgesic choice that prevents central sensitization in multiple sites along the pain pathways. Although most studies reported that various agents/techniques used for PA have potential in controlling postoperative pain, none of them has obvious superiority. Negative clinical findings are still not uncommon. On the basis of better understanding of pain mechanism, choosing a suitable analgesic approach (either alone or in combination) is essential for postoperative pain control. In PA, we should focus on attenuating the impact of the noxious stimuli in advance, but not just the time.

Till now, many questions remain unanswered about PA: Which approach is the best? What is the optimal dose to suppress the processes of peripheral and central sensitization? What's the necessity to extend the time of preemptive analgesia to postoperative period for reserving the initial advantage?

Most positive clinical and experimental results indicated that the pre-emptive could reduce postoperative pain. However, achieving the maximal analgesic effect of PA is still a challenge. Futher studies are needed to find a better comprehensive approach.

\section{Abbreviations}

COX: Cycloxygenase enzymes; NMDA antagonists: N-methyl-D-aspartate receptor antagonists; NSAIDs: Nonsteroidal anti-inflammatory drugs;

TKA: Total knee arthroplasty; $\gamma$-aminobutyric acid analogues: GABA analogues

\section{Acknowledgements}

None.

\section{Authors' contributions}

ZC, WB, SP and XZ undertook data management and analysis. All authors have approved the final manuscript.

\section{Funding}

Changzhou Science and Technology Bureau (NO.20180041).

\section{Availability of data and materials}

Data sharing not applicable to this review as no datasets were generated or analysed during this review.

Ethics approval and consent to participate Not applicable. 


\section{Competing interests}

The authors declare that they have no competing interests.

\section{Author details}

'Department of Orthopaedics, Changzhou Traditional Chinese Medical Hospital, Nanjing University of Traditional Chinese Medicine, 25 North Heping Road, Changzhou 213000, Jiangsu Province, China. ${ }^{2}$ Department of Arthroplasty, The First People's Hospital of Changzhou, Changzhou 213003, China.

Received: 14 February 2019 Accepted: 6 September 2019 Published online: 22 October 2019

\section{References}

1. Jasper $L L$, Jones CA, Mollins J, Pohar SL, Beaupre LA. Risk factors for revision of total knee arthroplasty: a scoping review. BMC Musculoskelet Disord. 2016;17:182

2. Zhuang Q, Bian Y, Wang W, Jiang J, Feng B, Sun T, et al. Efficacy and safety of postoperative intravenous Parecoxib sodium followed by ORal CElecoxib (PIPFORCE) post-total knee arthroplasty in patients with osteoarthritis: a study protocol for a multicentre, double-blind, parallel-group trial. BMJ Open. 2016:6:e011732.

3. Chughtai M, Elmallah RK, Cherian JJ, Mistry JB, Harwin SF, Mont MA. Rehabilitation and pain management modalities in total knee arthroplasty. J Knee Surg. 2016;29(3):179.

4. Horlocker TT. Pain management in total joint arthroplasty: a historical review. Orthopedics. 2010;33(9 Suppl):14-9.

5. Kissin I. Preemptive analgesia. Anesthesiology. 2000;93:1138-43.

6. Crile GW. The kinetic theory of shock and its prevention through anociassociation (shockless operation). Lancet. 1913;185:7-16.

7. Woolf CJ, Chong M-S. Preemptive analgesia--treating postoperative pain by preventing the establishment of central sensitization. Anesth Analg. 1993;77: 362-79

8. Woolf CJ. Evidence for a central component of post-injury pain hypersensitivity. Nature. 1983:308:386-8.

9. Bach S, Noreng MF, Tjellden NU. Phantom limb pain in amputees during the first 12 months following limb amputation, after pre-operative lumbar epidural blockade. Pain. 1988;33:297-301.

10. Coderre TJ, Catz J, Vaccarino AL, Melzack R. Contribution of central neutoplasticity to pathological pain: review of clinical and experimental evidence. Pain. 1993;52:259-85.

11. Vadivelu N, Mitra S, Schermer E, Kodumudi V, Kaye AD, Urman RD. Preventive analgesia for postoperative pain control: a broader concept. Local Reg Anesth. 2014;29(7):17-22.

12. Helander EM, Menard BL, Harmon CM, Homra BK, Allain AV, Bordelon GJ, et al. Multimodal analgesia, current concepts, and acute pain considerations. Curr Pain Headache Rep. 2017;21:3.

13. Skinner HB, Shintani EY. Results of a multimodal analgesic trial involving patients with total hip or total knee arthroplasty. Am J Orthop (Belle Mead NJ). 2004;33:85-92

14. Wong EM, Chan SW, Chair SY. Effectiveness of an educational intervention on levels of pain, anxiety and self-efficacy for patients with musculoskeletal trauma. J Adv Nurs. 2010;66(5):1120-31.

15. Yeom JH, Shim JH. Effect of preemptive analgesia on postoperative pain after total knee arthroplasty. Korean J Anesthesiol. 2005:49(6):S2-4.

16. Power I, Smith G. Postoperative pain. In: Aitkenhead AR, Rowbotham DJ, Smith G, editors. Text book of anaesthesia. 4th ed; 2001. p. 545.

17. Ronald MD. Acute postoperative pain. In: Miller RD (ed) Anesthesia 3rd ed. 1990. p. 135-6.

18. Dahl JB, Møiniche S. Pre-emptive analgesia. Br Med Bull. 2004;71:13-27.

19. Safiya IS, Bheemas BA. Novel concepts of analgesia for post operative pain: multimodal analgesia. Int J Biomedical Res. 2014;5(4):233-7.

20. Kelly DJ, Ahmad M, Brull SJ. Preemptive analgesia; recent advances \& current trends. Can J Anaesth D\&C. 2001:48:1091-101.

21. White PF. The changing role of non-opioid analgesic techniques in the management of postoperative pain. Anesth Analg. 2005;101:S5-22.

22. Krzyzanowska A, Pittolo S, Cabrerizo M, et al. Assessing nociceptive sensitivity in mouse models of inflammatory and neuropathic trigeminal pain. J Neurosci Methods. 2011;201(1):46-54.

23. Kashefi $\mathrm{P}$, Honarmand A, Safavi M. Effects of preemptive analgesia with celecoxib or acetaminophen on postoperative pain relief following lower extremity orthopedic surgery. Adv Biomed Res. 2012;1:66. https://doi.org/10 4103/2277-9175.100197.

24. Boonriong T, Tangtrakulwanich B, Glabglay P, Nimmaanrat S. Comparing etoricoxib and celecoxib for preemptive analgesia for acute postoperative pain in patients undergoing arthroscopic anterior cruciate ligament reconstruction: a randomized controlled trial. BMC Musculoskelet Disord. 2010;11:246. https://doi.org/10.1186/1471-2474-11-246.

25. Jianda X, Yuxing Q, Yi G, Hong Z, Libo P, Jianning Z. Impact of preemptive analgesia on inflammatory responses and rehabilitation after primary total knee arthroplasty: a controlled clinical study. Sci Rep. 2016;6:30354. https:// doi.org/10.1038/srep30354

26. O'Hanlon D, Thambipillai T, Colbert ST, Keane PW, Given FH. Timing of preemptive tenoxicam is important for postoperative analgesia. Can J Anesth. 2001;48:162-6.

27. Malmberg AB, Yaksh TL. Hyperalgesia mediated by spinal glutamate or substance $P$ receptor blocked by spinal cyclooxygenase inhibition. Science. 1992:257:1276-9.

28. Yaksh TL, Dirig DM, Malmberg AB. Mechanism of action of nonsteroidal anti-inflammatory drugs. Cancer Invest. 1998;16:509-27.

29. Murphy DF, Medley C. Preoperative indomethacin for pain relief after thoracotomy: comparison with postoperative indomethacin. $\mathrm{Br} J$ Anaesth. 1993;70:298-300.

30. Luo L, Wuesenfeld-Hallin Z. Differential effects of pre-treatment with intrathecal or intravenous morphine on the prevention of spinal cord hyperexcitability following sciatic nerve section in the rat. Acta Anaesthesiol Scand. 1996:40(1):91-5.

31. Campiglia L, Cappellini I, Consales G, Borracci T, Vitali L, Gallerani E, et al. Premedication with sublingual morphine sulphate in abdominal surgery. Clin Drug Investig. 2009;29(Suppl 1):25-30.

32. Wilson RJ, Leith S, Jackson IJ, Hunter D. Pre-emptive analgesia from intravenous administration of opioids. No effect with alfentanil. Anaesthesia. 1994:49:591-3.

33. Chong KC, Sulaiman AR, Yusof Ml, et al. The effectiveness of intravenous morphine infusion as preemptive analgesia in preventing phantom limb pain following lower limb amputation. Malaysian Orthop J. 2010;4(3):3-6.

34. McQuay HJ, Dawn C, Moore RA. Postoperative orthopaedic pain-the effect of opiate premedication and local anaesthetic blocks. Pain. 1988;33:289-91.

35. Oliveira CM, Sakata RK, Issy AM, et al. Ketamine and preemptive analgesia. Revbrasanestesiol. 2004;54(5):739-52.

36. Rafier MR, Aghadavoudi O, Rezvani M, Poorqasemian M. Evaluation of preemptive analgesia with dextromethorphan gargling in patients undergoing tonsillectomy. J Res Clin Sci. 2012;17(2):201-4.

37. Yeh CC, Ho ST, Kong SS, et al. Absence of the preemptive analgesic effect of dextromethorphan in total knee replacement under epidural anesthesia. Acta Anaesthesiol Sin. 2000;38(4):187-93.

38. Coughlin SM, Karanicolas PJ, Emmerton-Coughlin HM, Kanbur B, Kanbur S, Colquhoun PH. Better late than never? Impact of local analgesia timing on postoperative pain in laparoscopic surgery: a systematic review and metaanalysis. Surg Endosc. 2010;24:3167-76.

39. Pogatski Zahn EM, Zahn PK. From preemptive to preventive. Curr Opin Anaesthesiol. 2006:19:551-5.

40. Hong JY, Lin KT. Effect of preemptive epidural analgesia on cytokine response and postoperative pain in laparoscopic radical hysterectomy for cervical cancer. Reg Anesth Pain Med. 2008;33:44-51.

41. Tverskoy M, Cozacov C, Ayache M, Bradley EL, Kissin I. Postoperative pain after inguinal herniorrhaphy with different types of anesthesia. Anesth Analg. 1990;70:29-35.

42. Parlow JL. An unexpected benefit of pre-emptive rectal analgesic administration: the "key" to postoperative analgesia. JAMC. 2000;163(12): $1576-7$

43. Gordon SM, Dionne RA, Brahim J, Jabir F, Fubner R. Blockade of peripheral neuronal barrage reduces postoperative pain. Pain. 1997;70:209-15.

44. Dahl V, Raeder JC, Ernø PE, et al. Pre-emptive effect of pre-incisional versus post-incisional infiltration of local anaesthesia on children undergoing hernioplasty. Acta Anaesthesiol Scand. 1996;40(7):847-51.

45. Reuben SS, Sklar J, El-Mansouri M. The preemptive analgesic effect of intraarticular bupivacaine morphine after ambulatory arthroscopic knee surgery. Anesth Analg. 2001:92:923-6.

46. Dirks J, Hilsted KL, Moiniche S, Dahl JB. Mechanism of post operative pain: clinical indication for a contribution of central neural sensitization. Anaesthesiology. 2002;97:1591-6. 
47. Field MJ, Cox PJ, Stott E, Melrose H, Offord J, Su TZ, et al. Identifi cation of the alpha-2delta-1 subunit of voltage-dependent calcium channels as a molecular target for pain mediating the analgesic actions of pregabalin. PNAS. 2006:103:17537-42.

48. Dahl JB, Mathiesen O, Moiniche S. Protective premedication;an option with gabapentin and related drugs? A review of gabapentin and pregabalin in the treatment of post-operative pain. Acta Anaesthesiol Scand. 2004;48: $1130-6$.

49. Saraswat V, Arora V. Preemptive gabapentin vs pregabalin for acute postoperative pain after surgery under spinal anaesthesia. Indian J Anaesth. 2008:52:829-34.

\section{Publisher's Note}

Springer Nature remains neutral with regard to jurisdictional claims in published maps and institutional affiliations.

Ready to submit your research? Choose BMC and benefit from:

- fast, convenient online submission

- thorough peer review by experienced researchers in your field

- rapid publication on acceptance

- support for research data, including large and complex data types

- gold Open Access which fosters wider collaboration and increased citations

- maximum visibility for your research: over $100 \mathrm{M}$ website views per year

At BMC, research is always in progress.

Learn more biomedcentral.com/submissions 